\section{Prevalence of musculoskeletal disorders among plastics industry workers}

\author{
Prevalência de distúrbios musculoesqueléticos em \\ trabalhadores da indústria plástica
}

\begin{abstract}
1 Faculdade de Medicina da Bahia, Universidade Federal da Bahia, Salvador, Brasil. 2 Faculdade de Medicina, Universidade Federal de Minas Gerais, Belo Horizonte, Brasil.

Correspondence R. C. P. Fernandes Faculdade de Medicina da Bahia, Universidade Federal da Bahia.

Av. Reitor Miguel Calmon s/n, Salvador, $B A$

40110-100, Brasil.

ritafernandes@ufba.br
\end{abstract}

\begin{abstract}
The prevalence of musculoskeletal disorders among workers in the plastics industry in Salvador, Bahia State, Brazil was estimated. Cases were defined by reported symptoms of pain in the previous 12 months, lasting more than a week or having monthly minimum frequency, which had given rise to restrictions at work or to seeking medical attention, or where respondents had a severity score greater than or equal to 3 (on a numerical scale of 0 to 5). A stratified proportional random sample of 577 workers was studied. The prevalence of musculoskeletal disorders, considering of all body segments, was 50.1\%. The prevalence of musculoskeletal disorders was higher among women than among men at distal upper extremities (34.6\% and $11.6 \%$ respectively) and also in the region of the neck, shoulder or upper part of the back (27.4\% and $17.6 \%$ respectively). There was no difference between genders for the prevalence of lower back pain (21.2\% and $21.4 \%$ respectively); $65 \%$ of cases in this region had reports of pain in the previous seven days. Due to the importance and prevalence of musculoskeletal disorders, it is necessary that their measurement in epidemiological studies be done properly.

Cumulative Trauma Disorders; Musculoskeletal Diseases; Occupational Health
\end{abstract}

Rita de Cássia Pereira Fernandes 1 Fernando Martins Carvalho 1 Ada Ávila Assunção 2

\section{Introduction}

Musculoskeletal disorders are a major public health problem in industrialized and developing countries $1,2,3,4,5$. Over the past_twenty years, the international literature has consistently shown the importance of musculoskeletal disorders as a public health problem. In the USA, over one million workers per year are away from work due to such disorders 1 . The total annual cost associated with these disorders, including all indirect costs, is estimated at around one trillion dollars, equivalent to nearly $10 \%$ of the USA's gross domestic product 3 .

In European Union countries, prevalence rates of $30 \%$ and $40 \%$ of musculoskeletal disorders are recorded among workers in the Netherlands and Belgium, respectively. In Italy, 60\% of musculoskeletal disorders are recognized as occupational diseases. In France, musculoskeletal disorders accounted for 40\% (2,602 cases) of occupational diseases in 1992, and for $63 \%$ (5,856 cases) in 1996. In the UK it is estimated that 5.4 million working days are lost annually due to work-related neck and upper limbs musculoskeletal disorders, accounting for approximately one work month per case. It is estimated that in the period 2004-2005, 11 million days of work were lost in the UK due to musculoskeletal disorders 4,6 .

Changes that have occurred in the world of work, particularly in recent decades those related 
to the intensification of repetitive activities, certainly contribute to the absolute increases in the occurrence of musculoskeletal disorders. The increasing precariousness of work, a contemporary phenomenon, particularly involving the female labor force, has contributed to the proliferation of this form of illness.

In Brazil, the magnitude of the occurrence of musculoskeletal disorders is little known among workers who are currently in active employment, despite the high financial and social costs arising from temporary incapacity for work and disability retirements.

As a result of the non-existence of an information system for occupational morbidity in Brazil, there are no data on the occurrence of these disorders for the entire working population, even for clinical conditions that entail work disability. This hampers a more accurate assessment of the magnitude of the problem in the country. Data from the National Social Security Institute (INSS) are restricted to workers in formal employment who are beneficiaries of work place accident insurance. Still, the musculoskeletal disorders (or work-related musculoskeletal disorders) are the most commonly reported work-related illnesses in Brazil in recent years (Núcleo de Estudos e Análise em Saúde do Trabalhador/Centro Estadual de Referência em Saúde do Trabalhador/SUS-Bahia. Situação da saúde do trabalhador no Brasil e na Bahia: perfil epidemiológico. http://www.saude. ba.gov.br/cesat/Informacoes/SituacaoST_2007. pdf, accessed on 26/Nov/2009). In 2007, nearly half of the diagnoses of occupational diseases recorded by the INSS were cases of synovitis, tenosynovitis, and back and shoulder injuries, which represent some of the diseases catalogued as musculoskeletal disorders 7 .

This scenario justifies the studies on the prevalence of musculoskeletal disorders among different professional categories, aiming to contribute to a more effective diagnosis of the situation in the country. Furthermore, it should be noted that it is likely that many workers who are in active employment have musculoskeletal disorders expressed as pain or discomfort (musculoskeletal symptoms), before the clinical progression towards an incapacitating disorder becomes incompatible with the execution of tasks, leading to sick leave. Thus, studies on the prevalence of musculoskeletal disorders in the active working population, ie employees who supposedly have minor clinical conditions - which have not yet caused worker disability - may help prevent progression to incapacitating clinical conditions. Epidemiological studies using validated epidemiological tools can generate good quality data to enable a more accurate estimate of the preva- lence of musculoskeletal disorders among the population.

This study aims to estimate the prevalence of musculoskeletal disorders in general and per body segment, in a population of industrial workers, and will describe criteria for the characterization of musculoskeletal disorders, in order to contribute to further studies in other professional categories. Once the described case criteria are adopted, a comparison of results will be possible.

\section{Methods}

A prevalence study was conducted on a target population that included all workers employed in maintenance and operational activities in the plastics industry in the Metropolitan Region of Salvador city. All companies with more than 35 employees were eligible. All small and mediumsized plastics industry companies were identified based on the following sources: a list provided by the Federation of Industries of the State of Bahia (FIEB), a list of members of the Plastics Industries Association, and information provided by the Oil and Chemical Workers Union.

From a total of 1,177 workers, a stratified random sample was selected that was proportional to the number of employees in each plant. The minimum size of the sample, 557 individuals, was calculated assuming a degree of absolute accuracy of $4 \%$, confidence level of $95 \%$, expected prevalence of $50 \%$ and a design effect of 1.4. In order to include possible losses, a decision was made to enlarge the sample (581) beyond the minimum size originally calculated. Selected workers who were in temporary paid sick leave were contacted in order to participate in the study.

Each worker answered a questionnaire during working hours, at a specific place, in the year 2002. The team of interviewers received prior training. The questionnaire contained questions on socio-demographics, current and previous occupational history, including types of employment, whether formal or informal, working hours, number of hours worked in the previous week, physical and psychosocial demands at work; questions on tobacco use, medicine usage, alcohol consumption, household activities, physical fitness and sporting activities; questions on musculoskeletal disorders and other health information (history of bone fractures, history of diabetes mellitus, rheumatoid arthritis and hypothyroidism).

The questionnaire used to identify cases of musculoskeletal disorders was a Portuguese translation of the Nordic Musculoskeletal Ques- 
tionnaire (NMQ) ${ }^{8}$ done by the main author of this study. The questions assess severity, duration and frequency of symptoms in all body areas. The NMQ, reduced version 9 , is a widely used instrument to measure the prevalence of musculoskeletal disorders. The inclusion of questions to assess severity, duration and frequency of symptoms in all body segments, in the expanded version, aimed at improving the specificity of the symptomatology.

The case of musculoskeletal disorder was defined as the occurrence of pain in one or more of the following body parts: fingers, wrists, hands, forearms, elbows, neck, shoulder, upper region of the back, lower back, hips and thighs, knees, legs or ankles, in the previous twelve months. Symptoms should last more than one week or have monthly minimum frequency; they should be accompanied by at least one of the following signs of severity: score $\geq 3$ (on a 0 to 5 scale) with anchors at the ends (no pain to unbearable pain); seeking of medical attention for the problem; absence from work (official or not), change of work due to health restrictions 8 . The prevalence of pain in the previous twelve months was also described for each body segment, without the severity criteria, for purposes of comparison with literature data, considering that some studies do not use severity criteria, but only the record of pain in the previous twelve months. A case of pain refers to this general complaint of pain in the previous twelve months, for which each individual had the option to reply yes or no, while musculoskeletal disorder will designate cases of pain with the definition adopted above, using the severity criteria.

For the case of musculoskeletal disorder, once the question on the occurrence of pain in the previous twelve months was asked, for each body part mentioned in the answer, the individual was asked to add: the side that bothered him or her; the year that he or she noticed the problem; the usual duration of the problem (with the options: 1 - less than one hour; 2 - over one hour, up to one day; 3 - more than one day, up to one week; 4-more than one week, up to one month;5-more than one month, up to six months; 6 - more than six months); how many episodes of the problem he or she had (with the options: 1 - it is constant, all the time; 2 - daily; 3 - once a week; 4 - once a month; 5 - every two or three months; 6 - every six months, or twice a year). After these questions for each body region, the individual was asked if he or she had experienced the problem in the previous seven days. If the answer was positive, he/she was asked to grade the pain on a 0 to 5 scale, where the lower end of the scale (0) represented "no pain", and the opposite end (5) had "unbearable pain". The individual was also asked whether he or she received medical treatment for the problem, how many work days were lost because of the problem, how many days he or she remained in light or restricted work because of the problem, if he or she changed work because of the problem and, finally, if he or she had suffered acute trauma (using as examples: bump, pull, sprain, dislocation) 8 .

In studies conducted in industry, usually the female population is excluded because the small their small sample size makes the analysis unfeasible. In this study, although the sample was not stratified by gender, the number of participating women allowed for their inclusion in the analysis. Therefore, it was decided to describe the frequency of musculoskeletal disorders by gender.

The programs used for data analysis were Epi Info 6.04 (Centers for Disease Comtrol and Prevention, Atlanta, USA) and SPSS 9.0 (SPSS Inc., Chicago, USA).

The research project was approved by the Research Ethics Committee at the Public Health Institute of the Federal University of Bahia. Each participant signed an informed consent form before answering the epidemiological questionnaires. Before the questionnaires were used, workers were informed about the research objectives, what were the institutions in charge, and the fact that the plastics industries were contacted to grant access to factories by researchers, but did not have any participation in the survey.

\section{Results}

Of the 581 workers, only four employees refused to participate in the survey. A total of 577 workers were studied. Men accounted for $69 \%$ of the sample.

The consumption of alcohol at least once a week was reported by $43 \%$ of men and nearly $20 \%$ of women. The use of tobacco was $7.3 \%$ among women and there was a higher proportion of smokers among men (14.3\%). About 28\% of women and $37.6 \%$ of men were overweight or obese. Thirteen percent had children two years of age or younger (data not shown).

The proportion of workers who reported suffering from diabetes mellitus was $1.2 \%$; rheumatoid arthritis, $2.4 \%$; hypothyroidism, $1.4 \%$ (data not shown).

Data on working hours, extra shifts, overtime, employment time (whether formal or informal) and weekly hours at factory work were presented in another article 10 , which also includes data on weekly hours devoted to housework by men and women. 
The prevalence of pain in at least one of the body segments in the previous twelve months was $64 \%$. However, after applying the criteria of duration, frequency and severity, the prevalence was $50.1 \%$. Therefore, this prevalence refers to musculoskeletal pain lasting more than a week or having a minimal frequency of once per month, that caused some incapacity for work or led to the seeking of medical assistance, having severity equal to or greater than 3 , on a 0 to 5 scale. Based on these criteria, the prevalence of musculoskeletal disorders in the upper limbs, including the distal extremities and neck region, shoulder and upper part of the back was $30.8 \%$. Taking them separately, the musculoskeletal disorders in the region of the neck, shoulder or upper part of the back were reported by $20.6 \%$ of workers, and musculoskeletal disorders in the distal extremities were reported by $18.7 \%$. The prevalence of musculoskeletal disorders in the lumbar region was $21.3 \%$ (Table 1 ).

Women had a prevalence of musculoskeletal disorders three times higher than men in the distal upper extremities $(34.6 \%$ and $11.6 \%$, respectively) and 1.5 times higher in the region of the neck, shoulder or upper part of the back $(27.4 \%$ and $17.6 \%$, respectively). There was no difference between genders for the prevalence of lower back pain $(21.2 \%$ and $21.4 \%$ respectively) (Table 2$)$.

Among those who reported musculoskeletal disorders in the lumbar region in the previous twelve months, $65 \%$ had experienced pain in the previous seven days, the same happening for cases of musculoskeletal disorders in the region of the neck, shoulder and upper part of the back (64.7\%). More than half of those who reported musculoskeletal disorders at distal upper extremities during the previous twelve months said that the pain also occurred in the previous seven days (Table 3).

\section{Discussion}

The prevalence of musculoskeletal disorders among workers of the plastics industry who were in full working activity was high. The results show that a significant percentage of men and women from the industrial workers population are working with musculoskeletal pain.

The use of severity criteria allowed to identify prevalence of musculoskeletal symptoms of medium to high severity, ie, lasting more than a week or that had monthly minimum frequency, which in addition, scored 3 or higher on a 0 to 5 scale, or had symptoms that prompted the seeking of medical assistance or caused some restriction of work or absence from work. Considering that the prevalence of musculoskeletal disorders refers to workers who are in active labor, that is, it refers to male and female subjects working while in pain, that prevalence constitutes an important source of morbidity in this population, also taking into account the high probability of progression to clinical conditions that determine incapacity for work.

The few studies identified on the prevalence of musculoskeletal pain among workers,

Prevalence of pain and musculoskeletal disorders * among plastics industry workers, according to body segment. Salvador, Bahia State, Brazil.

\begin{tabular}{|c|c|c|c|c|c|c|}
\hline \multirow[t]{2}{*}{ Body segment } & \multicolumn{3}{|c|}{$\begin{array}{l}\text { Pain in the previous twelve months } \\
\qquad(n=577)\end{array}$} & \multicolumn{3}{|c|}{$\begin{array}{l}\text { Musculoskeletal disorders } \\
\qquad(\mathrm{n}=577)\end{array}$} \\
\hline & $\mathrm{n}$ & $\%$ & $95 \% \mathrm{Cl}$ & $\mathbf{n}$ & $\%$ & $95 \% \mathrm{Cl}$ \\
\hline In some region (upper limbs, lower limbs or spine) & 369 & 64.0 & $59.1-68.9$ & 289 & 50.1 & 44.3-55.9 \\
\hline Distal upper extremities or neck or shoulders or upper back & 223 & 38.6 & $32.2-45.0$ & 178 & 30.8 & $24.0-37.5$ \\
\hline Distal upper extremities or neck or shoulders & 202 & 35.0 & $28.4-41.6$ & 160 & 27.7 & $20.8-34.6$ \\
\hline Distal upper extremities (elbow, forearm, wrist, hands or fingers) & 142 & 24.6 & $17.5-31.7$ & 108 & 18.7 & $11.3-26.0$ \\
\hline Upper back or lumbar region & 206 & 35.7 & $29.2-42.2$ & 152 & 26.3 & $19.3-33.3$ \\
\hline Neck, shoulders or upper back & 152 & 26.3 & $19.3-33.3$ & 119 & 20.6 & $13.3-27.9$ \\
\hline Neck or shoulder & 119 & 20.6 & $13.3-27.9$ & 89 & 15.4 & $7.9-22.9$ \\
\hline Neck & 65 & 11.3 & $3.6-19.0$ & 42 & 7.3 & $0.0-15.2$ \\
\hline Shoulder & 84 & 14.6 & $7.0-22.1$ & 64 & 11.1 & $3.4-18.8$ \\
\hline Lumbar region & 167 & 28.9 & $22.0-35.8$ & 123 & 21.3 & $14.1-28.5$ \\
\hline
\end{tabular}

* Reference to pain in the previous twelve months, lasting more than one week or having monthly minimum frequency, which led to the seeking of medical assistance, or being away from work, or change jobs, with severity score 3 or greater on a 0 to 5 scale. 
Prevalence of musculoskeletal disorders * among plastics industry workers, according to body segment and gender. Salvador, Bahia State, Brazil.

\begin{tabular}{|c|c|c|c|c|c|c|}
\hline \multirow[t]{2}{*}{ Body segment } & \multicolumn{3}{|c|}{ Women/Female $(n=179)$} & \multicolumn{3}{|c|}{ Men/Male $(n=398)$} \\
\hline & $\mathbf{n}$ & $\%$ & $95 \% \mathrm{Cl}$ & $\mathbf{n}$ & $\%$ & $95 \% \mathrm{Cl}$ \\
\hline In some region (upper limbs, lower limbs or spine) & 120 & 67.0 & $58.6-75.4$ & 169 & 42.5 & $35.0-50.0$ \\
\hline Distal upper extremities (elbow, forearm, wrist, hands or fingers) & 62 & 34.6 & $22.8-46.4$ & 46 & 11.6 & $2.3-20.8$ \\
\hline Neck, shoulders or upper back & 49 & 27.4 & $14.9-39.9$ & 70 & 17.6 & $8.7-26.5$ \\
\hline Lumbar region & 38 & 21.2 & $8.2-34.2$ & 85 & 21.4 & $12.7-30.1$ \\
\hline
\end{tabular}

* Reference to pain in the previous twelve months, lasting more than one week or having monthly minimum frequency, which led to the seeking of medical assistance, or being away from work, or changing jobs, with severity score 3 or greater on a 0 to 5 scale.

Proportion of pain in the previous seven days in cases of musculoskeletal disorders *, among plastics industry workers. Salvador, Bahia State, Brazil.

\begin{tabular}{|c|c|c|c|c|}
\hline \multirow[t]{3}{*}{ Body segment } & \multirow{2}{*}{\multicolumn{2}{|c|}{$\begin{array}{c}\text { Women/Female }(n=179) \\
\text { Yes }\end{array}$}} & \multirow{2}{*}{\multicolumn{2}{|c|}{$\begin{array}{c}\text { Men/Male }(n=398) \\
\text { No }\end{array}$}} \\
\hline & & & & \\
\hline & $\mathbf{n}$ & $\%$ & $\mathbf{n}$ & $\%$ \\
\hline Distal upper extremities (elbow, forearm, wrist, hands or fingers) & 59 & 54.6 & 49 & 45.4 \\
\hline Neck, shoulders or upper back & 77 & 64.7 & 42 & 35.3 \\
\hline Lumbar region & 80 & 65.0 & 43 & 35.0 \\
\hline
\end{tabular}

* Reference to pain in the previous twelve months, lasting more than one week or having monthly minimum frequency, which led to the seeking of medical assistance, or being away from work, or changing jobs, with severity score 3 or greater on a 0 to 5 scale.

in Brazil, describe the pain without regard to any criterion of specificity of symptoms, ie no definition of frequency or duration of pain, and independent of severity. In this case, the comparison with these studies 11,12,13 can be made for prevalences described in the present study as "case of musculoskeletal pain", ie situations in which the individual only answered whether he or she experienced pain in the previous twelve months. A study conducted among dentists 11, using self-administered questionnaires sent by mail, found an overall prevalence of musculoskeletal symptoms of 58\%. This finding of general pain symptom can be compared to the finding of $64 \%$ in the population of workers in the present study. Picoloto \& Silveira 12, studying the industrial population of metal workers, found an overall prevalence of pain of $75.2 \%$. On the other hand, a study of workers in the ceramic industry 13 found a $38.5 \%$ prevalence of pain in the previous twelve months, using a population of 90 individuals. This prevalence was higher among women, (46\%), than among men, (16\%).

The other findings of prevalence by body segment from the study among dentists 11 are com- parable to those of the present study, with some differences. For example, the prevalence of neck pain $(20 \%)$ and shoulder pain (17\%) among dentists was higher than among industrial workers ( $11.3 \%$ and $14.6 \%$ respectively) and the prevalence of pain in distal upper extremities was similar $(22 \%$ and $24.6 \%$ respectively). However, the prevalence of pain including upper back pain or lumbar region pain in this population of plastics industries workers (35.7\%) was higher than among dentists $(21 \%)$. The finding of pain in the lumbar region $(28.9 \%)$ was more similar to the finding of $33 \%$ among workers in the ceramics industry 13 . Among ceramics workers 13 , the prevalence of pain in distal upper extremities was 35\%; in the neck, $9 \%$; in the shoulder, $9 \%$.

In a study of health care workers, nursing assistants and healthcare support workers, Fonseca 14 found high prevalences of musculoskeletal disorders for all the body segments studied, all of them higher than the prevalence rates found in this study. Fonseca 14 used the same criteria used in this study for case definition of musculoskeletal disorder. To the finding of $50.1 \%$ prevalence in any body part among industrial workers found 
here, it is possible to compare the prevalence of $83.4 \%$ found by Fonseca 14 . For musculoskeletal disorders in the lumbar region, the prevalence among women from nursing 14 was $53.9 \%$ and among industrial workers was $21.3 \%$; for distal upper extremities it was $32.8 \%$ and $18.7 \%$ respectively.

It is possible to accept that the characteristics of work tasks - which may entail different motor requirements for dissimilar body segments in unlike occupations and professional categories - explain the diversity of findings. From a biomechanical point of view, it is plausible to assume that nursing assistants and manufacturing industry workers have more back pain than dentists, but other explanatory factors should be explored. It is possible that factors associated with perception and recording of complaints are also responsible for differences in the prevalence of pain complaints among health care professionals 14. Moreover, nursing assistants or healthcare support workers studied by Fonseca 14 worked in a public hospital. One can not exclude the possibility of information bias due to overestimation of pain complaints by the latter.

In other countries, some cross-sectional studies on musculoskeletal pain in the previous twelve months show similar results, particularly for industrial workers. The overall prevalence of low back pain in this study (28.9\%) is comparable to $31 \%$ found among maintenance workers 15 , and $30 \%$ among industrial workers 16 . Other authors have found a higher prevalence of lower back pain than the present study, particularly among construction (54\%) 17 and metallurgical (50\%) workers 18 . Latko et al. 19, using "non-specific discomfort" as the measure of effect, found a prevalence of $36 \%$ for distal upper extremity symptoms lasting more than a week or having three episodes in the previous twelve months, among manufacturing workers. This prevalence is higher than the one in the present study (21.3\%), when only the duration of more than one week is considered or a minimum frequency of once per month as severity criterion, with no other criteria applied (data not shown).

The high proportions of pain in the previous seven days among those with musculoskeletal disorders may reveal that clinical conditions identified as musculoskeletal disorders are more serious, and occur among these workers on a recurring and permanent basis. The plight of Brazilian workers who have had to leave active employment is well known: they are assisted in referral centers for occupational health, or receive social security aid due to clinical conditions for chronic musculoskeletal pain - conditions commonly described as cases of repetitive strain injury 20 . In this study, however, workers in their workplaces, in active labor, were addressed. Therefore, it is about men and women who work while in pain, either on assembly lines or finishing departments, performing repetitive movements or load handling. Working while in pain entails a situation of morbidity that requires urgent control measures.

The comparison of results should always be made with some caution, considering the different circumstances of instrument usage, selfapplied or applied by interview, inside or outside the workplace. The questionnaire administered through interviews, as in this study, instead of self-applied, can ensure greater validity of the answers. This advantage has been reported by many authors, both with respect to inquiries about the symptoms and exposure 21,22.

In order to reduce information bias by overestimates of the complaint, in this study some procedures were adopted that would minimize the focus of research in musculoskeletal disorders 23 . Andersson et al. 24 found higher prevalences of symptoms when the population completed the questionnaire in the context of an assessment of musculoskeletal disorders than when responding to a more general health questionnaire, including questions about musculoskeletal disorders. Thus, the title used in the questionnaire of this study was Research on Health Conditions among Plastics Industry Workers; the survey on musculoskeletal symptoms was located at the end of the form, preceded by sections that asked about extra-labor physical activities and occupational characteristics, and followed by a section on other health information. It was also aimed to avoid the overestimation of exposure, which could occur more easily if the symptoms survey preceded the questions about exposure.

In general, the sensitivity of surveys on musculoskeletal symptoms is high 25,26 and sometimes specificity may be lower, affecting the accuracy of responses. The use of severity criteria may increase specificity, reducing false positives. However, studies of validity and reliability with the NMQ generally revealed high validity and reliability 9,26. In Brazil, a study by Pinheiro et al. 27 found good concurrent validity (an 86\% conformity/concordance) for the NMQ, short version 9 , when it was applied to bank employees, comparing symptom scoring/scores/recording by NMQ to the respondents' clinical history.

Different prevalence of musculoskeletal disorders for distal upper extremities and the region of the neck, shoulder or upper back, among men and women, have been found by other authors 28 . Neck, shoulder and upper part of the back should be described as a set, considering the difficulty 
in specifying the origin of symptoms that affect some segment of this region. These segments act as a functional unit, ie, the demands would act on the unit as a whole 1,26,29.

The differences between men and women point to the need for control policies of musculoskeletal disorders that reflect this gender difference in the occurrence of diseases. Several factors have been discussed and investigated as determinants of these differences, among these occupational and extra labor factors.

Nearly a third of the working population of this study were women, employed primarily in production activities. Although the situation is still disadvantageous for women with regard to career opportunities in companies, particularly with regard to the tasks they perform in the factories studied, the plastics industry marketplace contains a large contingent of women 30 . An ergonomic study conducted with a portion of the population that is the object of this study revealed that the fear of losing employment was a relevant characteristic among women. This may indicate the existence of a situation of increasing precariousness of work, having as an impact a greater occupational exposure to repetitive work, subject to anomalous postures, and under time pressure ${ }^{31}$. These work conditions are factors associated with greater incidences of musculoskeletal disorders.

Cigarette smoking among women was only $7.3 \%$, but this result is comparable to that found by Fonseca 14 when studying a female population of nursing assistants and healthcare support workers. The consumption of alcohol at least once a week for female industry workers (20\%) was similar to that found among female nursing assistants and healthcare support workers (19.5\%). However, there is still a marked difference between these two populations regarding the body mass index (BMI), with $49 \%$ of overweight or obesity among healthcare workers, and $28 \%$ for industry workers. The possibility that a female population understates their respective weights could not explain the difference found, because both populations compared are formed by women. In this case, the possibility must be considered that integration in different work environments - services sector and industry - interferes in lifestyles and places different demands on the body.

Co-morbidity in this population was far below the co-morbidity in the general population, especially for diabetes. It is possible that the healthy worker effect is responsible for the selection of this labor force that has no chronic diseases, like diabetes, which may entail the need of adapting the work to the limitations of the worker, and a greater absenteeism.

Considering the potential of progression of clinical conditions of musculoskeletal disorders described in this study, the estimated prevalences are of importance for this population. The possibility of progression towards chronic clinical conditions for musculoskeletal disorders, having greater severity and the consequence of employment disability, should lead to control measures of these disorders in this working population.

The interest of this study, in addition to estimating the prevalence of musculoskeletal disorders in a population of industrial workers, is to contribute to future investigations of musculoskeletal disorders in this country, which will enable a comparison of findings, with clear and stricter case definitions of musculoskeletal disorders, and identification of the most critical sectors of the economy as to its occurrence. Epidemiological research in the workplace is not easily feasible, especially in private companies, but expanding access to fully active workers is viable.

\section{Resumo}

Estimou-se prevalência de distúrbio musculoesquelético em trabalhadores da indústria de plástico, em Salvador, Bahia, Brasil. Casos foram definidos pelo relato de sintomas de dor nos últimos 12 meses, com duração maior do que uma semana ou freqüência mínima mensal, que haviam determinado restrição ao trabalho ou procura médica, ou tinham gravidade maior ou igual a 3 (numa escala numérica de 0 a 5). Estudou-se uma amostra aleatória estratificada proporcional de 577 trabalhadores. A prevalência de distúrbio musculoesquelético, considerando todos os segmentos corporais, foi de 50,1\%, sendo maior entre mulheres do que entre homens nas extremidades supe- riores distais (34,6\% e 11,6\%, respectivamente) e na região de pescoço, ombro ou parte alta do dorso $(27,4 \% e$ $17,6 \%$, respectivamente). Não houve diferença entre os sexos para a prevalência de lombalgia $(21,2 \%$ e 21,4\%, respectivamente) e 65\% dos casos nesta região apresentaram dor nos últimos sete dias. Devido à grande importância e prevalência dos distúrbios musculoesqueléticos, é necessário que a sua mensuração seja feita adequadamente, em estudos epidemiológicos.

Transtornos Traumáticos Cumulativos; Doenças Musculosqueléticas; Saúde do Trabalhador 


\section{Contributors}

R. C. P. Fernandes contributed to the conception and design of the study, acquisition, analysis and interpretation of data; drafted the manuscript and approved the version to be published. F. M. Carvalho contributed to the conception and design of the study and interpretation of data; revised the manuscript and approved the version to be published. A. A. Assunção contributed to the conception and design of the study and interpretation of data; revised the manuscript, and made important contributions on the content.

\section{References}

1. National Research Council/Institute of Medicine. Musculoskeletal disorders and the workplace: low back and upper extremities. Washington DC: National Academy Press; 2001.

2. Melhorn JM. Cumulative trauma disorders and repetitive strain injuries. The future. Clin Orthop Relat Res 1998; 351:107-26.

3. Melhorn JM, Gardner P. How we prevent prevention of musculoskeletal disorders in the workplace. Clin Orthop 2004; 419:285-96.

4. European Agency for Safety and Health at Work. Work-related musculoskeletal disorders: back to work report. Luxembourg: Office for Official Publications of the European Communities; 2007.
5. Marras WS, Cutlip RG, Burt SE, Waters TR. National occupational research agenda (NORA) future directions in occupational musculoskeletal disorder health research. Appl Ergon 2009; 40:15-22.

6. Buckle PW, Devereux JJ. The nature of work-related neck and upper limb musculoskeletal disorders. Appl Ergon 2002; 33:207-17.

7. Ministério da Previdência Social. Anuário estatístico da previdência social 2007. Seção IV: acidentes do trabalho. http://www.mpas.gov.br/conteudo Dinamico.php?id=559 (accessed on 16/Dec/2008).

8. Kuorinka I, Forcier L. Work related musculoskeletal disorders (WMSDs): a reference book for prevention. London: Taylor \& Francis; 1995. 
9. Kuorinka I, Jonsson B, Kilbom A, Vinterberg H, Biering-Sorensen F, Andersson G, et al. Standardised Nordic questionnaires for the analysis of musculoskeletal symptoms. Appl Ergon 1987; 18:233-7.

10. Fernandes RCP, Assunção AA, Silvany Neto AM, Carvalho FM. Musculoskeletal disorders among workers in plastic manufacturing plants. Rev Bras Epidemiol 2010; 13:11-20.

11. Santos Filho SB, Barreto SM. Atividade ocupacional e prevalência de dor osteomuscular em cirurgiões-dentistas de Belo Horizonte, Minas Gerais, Brasil: contribuição ao debate sobre os distúrbios osteomusculares relacionados ao trabalho. Cad Saúde Pública 2001; 17:181-93.

12. Picoloto D, Silveira E. Prevalência de sintomas osteomusculares e fatores associados em trabalhadores de uma indústria metalúrgica de Canoas RS. Ciênc Saúde Coletiva 2008; 13:507-16.

13. Melzer ACS, Iguti AM. Working conditions and musculoskeletal pain among Brazilian pottery workers. Cad Saúde Pública 2010; 26:492-502.

14. Fonseca NR. Distúrbios músculo-esqueléticos em trabalhadores de enfermagem [Dissertação de Mestrado]. Salvador: Universidade Federal da Bahia; 2009.

15. Burdorf A, Govaert G, Elders L. Postural loads and back pain of workers in the manufacturing of prefabricated concrete elements. Ergonomics 1991; 34:909-18.

16. Waters TR, Baron SL, Piacitelli LA, Anderson VP, Skov T, Haring-Sweeney M, et al. Evaluation of the revised NIOSH lifting equation. A cross-sectional epidemiologic study. Spine (Phila Pa 1976) 1999; 24:386-94.

17. Holmström EB, Lindell J, Moritz U. Low back and neck/shoulder pain in construction workers: occupational workload and psychosocial risk factors. Part 1: relationship to low back pain. Spine (Phila Pa 1976) 1992; 17:663-71.

18. Suadicani P, Hansen K, Fenger AM, Gyntelberg F. Low back pain in steelplant workers. Occup Med (Lond) 1994; 44:217-21.

19. Latko WA, Armstrong TJ, Franzblau A, Ulin SS, Werner RA, Albers JW. Cross-sectional study of the relationship between repetitive work and the prevalence of upper limb musculoskeletal disorders. Am J Ind Med 1999; 36:248-59.
20. Merlo ARC, Vaz MA, Spode CB, Elbern JLG, Karkow ARM, Vieira PRB. O trabalho entre prazer, sofrimento e adoecimento: a realidade dos portadores de lesões por esforços repetitivos. Psicol Soc 2003; 15:177-236.

21. Leijon O, Wiktorin C, Harenstam A, Karlqvist L. Validity of a self-administered questionnaire for assessing physical work loads in a general population. J Occup Environ Med 2002; 44:724-35.

22. Nordstrom DL, Vierkant RA, Layde PM, Smith MJ. Comparison of self-reported and expert-observed physical activities at work in a general population. Am J Ind Med 1998; 34:29-35.

23. Hays M, Saurel-Cubizolles MJ, Bourgine M, Touranchet A, Verge C, Kaminski M. Conformity of workers' and occupational health physicians' descriptions of working conditions. Int J Occup Environ Health 1996; 2:10-7.

24. Andersson K, Karlehagen S, Jonsson B. The importance of variations in questionnaire administration. Appl Ergon 1987; 18:229-32.

25. Björkstén MG, Boquist B, Talbäck M, Edling C. The validity of reported musculoskeletal problems. A study of questionnaire answers in relation to diagnosed disorders and perception of pain. Appl Ergon 1999; 30:325-30.

26. Baron S, Hales T, Hurrel J. Evaluation of symptom surveys for occupational musculoskeletal disorders. Am J Ind Med 1996; 29:609-17.

27. Pinheiro FA, Troccoli BT, Carvalho CV. Validação do Questionário Nórdico de Sintomas Osteomusculares como medida de morbidade. Rev Saúde Pública 2002; 36:307-12.

28. de Zwart BC, Frings-Dresen MH, Kilbom A. Gender differences in upper extremity musculoskeletal complaints in the working population. Int Arch Occup Environ Health 2001; 74:21-30.

29. Björkstén MG, Boquist B, Talbäck M, Edling C. Reported neck and shoulder problems in female industrial workers: the importance of factors at work and at home. Int J Ind Ergon 2001; 27:159-70.

30. Fernandes RCP, Assunção AA, Carvalho FM. Mudanças nas formas de produção na indústria e a saúde dos trabalhadores. Ciênc Saúde Coletiva 2010; 15 Suppl 1:1563-74.

31. Fernandes RCP, Assunção AA, Carvalho FM. Tarefas repetitivas sob pressão temporal: os distúrbios musculoesqueléticos e o trabalho industrial. Ciênc Saúde Coletiva 2010; 15:931-42.

Submitted on $05 /$ Jun/2010

Approved on 11/Aug/2010 